\title{
Perspectivas contemporâneas para a constituição de redes de políticas públicas
}

\section{Hermílio Santos*}

O estudo de políticas públicas se dedica em geral a analisar os seus conteúdos, seus impactos ou ainda o processo de sua formulação e implementação. O presente artigo irá se deter a este último aspecto. $\mathrm{O}$ tema proposto aqui será abordado em três momentos distintos. Em um primeiro momento discute-se a capacidade do Estado brasileiro cumprir, com eficiência, o papel de formulador e implementador dessas políticas. Em seguida será realizado um esforço tentativo de apontar uma possível alternativa para o processo de formulação de políticas públicas fundado na complexa interação de atores estatais e não-estatais através da constituição de redes de políticas públicas. Por último, serão analisados brevemente um exemplo que demonstra a incapacidade de otimizar os recursos públicos e privados na implementação de políticas públicas e um outro que demonstra precisamente a potencialidade para a constituição do que se convencionou chamar de "redes de políticas públicas".

Doutor em Ciência Política pela Freie Universität Berlin. Professor do Programa de PósGraduação em Ciências Sociais da PUCRS. hermilio@pucrs.br.

\begin{tabular}{|l|l|l|l|l|l|} 
Civitas & Porto Alegre & v. 5 & n. 1 & jan.-jun. 2005 & p. 59-68 \\
\hline
\end{tabular}




\section{I}

No início da década de 1990 prosperou uma avaliação de que a causa do que se convencionou chamar "crise do Estado brasileiro" residiria na sua incapacidade de processar as demandas excessivas, em dar conta da agenda sobrecarregada, em responder às pressões excessivas, além de diversos outros fatores provocados pela ampliação da participação política. Isto estaria provocando profundas incertezas no processo de governabilidade. Essas leituras da crise do Estado orientam-se pelas reflexões realizadas por Samuel Huntington. Segundo Huntington, as condições ótimas para a governabilidade estariam garantidas caso se dê um equilíbrio entre as demandas lançadas ao Estado e sua capacidade de administrá-las e atendê-las (Huntington, 1975).

Diferente deste diagnóstico, Eli Diniz (1998) afirma que o estrangulamento do Estado situar-se-ia, sobretudo, "no âmbito da execução das políticas, da capacidade de fazer cumprir as decisões tomadas e de assegurar a continuidade dos programas governamentais" (Diniz, 1998, p. 31). Analisando os governos após o processo de redemocratização, a autora identifica um aumento do poder despótico, através da concentração do poder decisório na cúpula tecno-burocrática, ao mesmo tempo em que ocorreria um debilitamento do poder infra-estrutural, através de uma forte crise fiscal, de uma crise de autoridade como resultado dos fracassos dos diversos planos de estabilização econômica e a erosão da capacidade do Estado de realizar suas funções básicas, como por exemplo, a garantia da ordem e da segurança.

Quanto à produção de políticas públicas, observa-se no período pósautoritário uma proliferação de decisões sem qualquer consulta ou transparência, "por um pequeno círculo que se localiza em instâncias enclausuradas na alta burocracia governamental" (Diniz, 1998, p. 34), o que fica bastante evidente não apenas na persistência, mas também na expansão do uso de medidas provisórias. Embora não seja difícil concordar que o Brasil pode ser considerado um país com democracia consolidada quanto aos chamados requisitos liberais clássicos: liberdade de organização, expressão e participação eleitoral, entre outros, trata-se de um regime deficitário, ainda segundo Diniz, "quanto à eficácia dos mecanismos de cobrança e de prestação de contas, inexistindo praticamente os instrumentos garantidores da responsabilização pública dos governantes diante da sociedade e de outras instâncias do poder" (Diniz, 1998, p. 38), ou seja, aquilo denominado de déficit de accoun- 
tability. Nos anos mais recentes, a entrada em vigor de algumas leis, notadamente da "lei de responsabilidade fiscal" têm contribuído para minimizar este déficit. Entretanto, o conceito de accountability vai além dos avanços representados pela limitação dos gastos públicos e da prestação das contas. Este envolveria ainda, entre outras coisas, atuar no sentido de gerar as condições para que aqueles que são afetados por programas ou políticas específicos sejam envolvidos de alguma maneira.

A partir disso, Diniz sugere que as categorias de governabilidade - entendida como as condições sistêmicas sob as quais se dá o exercício do poder, como a forma de governo, a relação entre os poderes e o sistema partidário e governança - entendida como a capacidade de ação estatal na formulação e implementação de políticas públicas - estejam interligadas como forma de superação da crise do Estado brasileiro.

Como podemos conceber maneiras de formular e implementar políticas públicas em que estejam combinadas a capacidade de governabilidade com uma boa governança? A seguir tentarei oferecer alternativas satisfatórias para esta questão.

Nesta seção proponho discutir como o Estado, em algumas democracias, tem procurado articular os interesses existentes na sociedade de uma tal maneira a garantir uma maior eficiência das políticas formuladas, sem, no entanto, fazer do Estado prisioneiro de interesses economicamente robustos. Tratase, então, de problematizar a maneira como o Estado se articula com atores não-estatais a fim de otimizar parte de suas funções.

A questão relevante que deve ser coloca a esta altura é saber de que maneira atores não-estatais podem contribuir para o processo de políticas públicas. A presença de grupos de interesse, por exemplo, é comumente percebida somente quando tentam sabotar medidas deliberadas. É em parte por esta razão que esses grupos gozam em geral de má reputação entre segmentos sociais e administradores públicos. Entretanto, é preciso que fique claro que entre os atores não-estatais devem ser incluídos não apenas os grupos de interesse.

Estudos recentes apontam para a tendência de se estudar todo o processo de formulação de políticas públicas. A principal preocupação está na tentativa 
de oferecer uma visão geral da participação dos diferentes atores ou da investigação das relações entre eles. Essa linha de pesquisa tem se tornado mais freqüente desde meados da década de 1980 e é caracterizada pela análise das redes de políticas (policy networks).

Por rede de políticas públicas entende-se a caracterização geral do processo de formulação de políticas na qual membros de uma ou mais comunidades de políticas estabelecem uma relação de interdependência. Alguns autores, como Marin e Mayntz (1991) chamam a atenção para o fato de que redes de políticas públicas não podem ser definidas unicamente através de sua interação interorganizacional, mas também pela sua função, a saber, a formulação e implementação de medidas. Onde é identificada a presença de redes - através da observação de atores que participam das negociações e consultas antes que as decisões sejam tomadas -, estas se concentram em temas setoriais ou específicos (como por exemplo no apoio ao desenvolvimento de novas tecnologias, no caso de política industrial).

Esta concepção do processo de formulação de políticas públicas tem como pano de fundo uma compreensão da sociedade em que diferentes atores interagem de uma maneira relativamente descentralizada. Isso significa que políticas públicas são o resultado de uma complexa interação entre agências estatais e organizações não-estatais. Rejeita-se com isso a abordagem que parte do Estado como o único ator relevante neste processo. A iniciativa para que um tema seja objeto de política pública pode ser tomada não apenas pelo Estado, mas também por agentes não-estatais. Aqui se estabelece uma distinção marcante entre a formulação de políticas através de rede de políticas públicas, de um lado, e através de dirigismo estatal, por outro lado. A formulação via rede não se baseia em comando e ordem, mas em negociação e intercâmbio. Este intercâmbio não significa, porém, que todos os atores se beneficiem igualmente da relação daí decorrente.

Ao contrário do que possa parecer, o Estado envolvido no processo de políticas públicas através de rede não é um Estado prisioneiro e fragilizado em sua ação. Trata-se de um Estado que perdeu suas pretensões de dirigismo, mas que não abdicou de seu papel de formulador e implementador de políticas. Entretanto, este papel tradicional passa a ser combinado com uma nova maneira de processar as demandas, a saber, quando atores não-estatais passam a estar incluídos ex ante na identificação de problemas e na proposição 
de soluções, inclusive com alguns desses atores assumindo parcela da responsabilidade em sua implementação. ${ }^{1}$

No Brasil, ainda são escassas as análises do processo de constituição de redes de políticas públicas. Diferentemente da grande maioria da literatura que trata da temática - que concentra a análise por um lado na capacidade do Estado de se articular com outros atores e, por outro lado, na incapacidade do Estado de prover todos os recursos necessários à formulação e implementação de políticas públicas -, no Brasil, não se poderia analisar esta realidade desconsiderando o desenvolvimento recente das organizações da sociedade civil.

$\mathrm{Na}$ definição de sociedade civil, formulada por Jean Cohen e Andrew Arato (1992), os movimentos sociais são entendidos como parte constitutiva da sociedade civil. Para esses autores, sociedade civil é uma esfera de interação social entre economia e estado, e é composta, sobretudo, pela esfera íntima (família, por exemplo), a esfera das associações (especialmente associações voluntárias), os movimentos sociais e formas de comunicação pública. Mais que constituindo a sociedade civil, os movimentos sociais são, para Cohen e Arato, o elemento dinâmico nos processos que devem realizar as potencialidades positivas das sociedades civis modernas. $\mathrm{O}$ que haveria de novo e positivo nos movimentos sociais é não apenas o abandono de ideais revolucionários em favor de reformas radicais, mas que a luta por essas reformas não estariam direcionadas única e principalmente ao Estado. Isso quer significar que a própria sociedade, e de maneira mais restrita os próprios movimentos sociais, seriam o alvo e a esfera capaz de processar essas reformas. Aqui não significa que o Estado tenha se tornado irrelevante, mas tão somente que o Estado passa a compartilhar sua importância com atores sociais situados na comunidade societária, tal como denominado na análise de Talcott Parsons. No Brasil, estaríamos nos afastando de maneira consistente daquela realidade em que o Estado cria, organiza e regula as sociedades, enfim, o Estado deixa de ser o centro da sociedade. Portanto, na constante tensão existente entre os diferentes subsistemas sociais (ou esferas), a comunidade societária vem se consolidando nas últimas décadas. Esta situação

Para uma análise de redes de políticas públicas neopluralistas e neocorporatistas, ver Santos (2002). 
contribui sobremaneira para criar um novo cenário no processo de formulação e implementação de políticas públicas.

Como na concepção desenvolvida por Cohen e Arato, Jeffrey Alexander também apresenta explicitamente a noção dos movimentos sociais como tradução da sociedade civil. Segundo Alexander, o desenvolvimento dos movimentos sociais como fenômenos relevantes só se tornou possível após o surgimento de uma sociedade civil independente. O vínculo dos movimentos sociais com a tentativa de ampliação da cidadania se deve - em oposição aos grupos de interesse, por exemplo - ao fato de pretensão de universalidade em sua atuação. Isso seria alcançado quando os movimentos sociais logram vocalizar problemas que são transferidos de uma especificidade particular para o conjunto da sociedade civil. É precisamente esse deslocamento, ou seja, a constituição de uma agenda mais ampla, que concede legitimidade aos movimentos sociais.

Situando-se entre o estado e o mercado, os movimentos sociais e as demais instituições da comunidade societária cumpririam um papel de fazer com que as políticas públicas implementadas passassem a adotar uma perspectiva menos centrada no Estado.

De acordo com Avritzer (1994), o surgimento da sociedade civil no Brasil associa-se a três fenômenos fundamentais: a) ao surgimento de atores sociais modernos e democráticos; b) à retomada da idéia, realizada por esses autores, de constituição de um espaço intermediário entre estado e sociedade e c) à constituição de estruturas legais apropriadas para a institucionalização das reivindicações da sociedade civil.

Os dois primeiros fenômenos estão vinculados ao surgimento de novos atores sociais, decorrência do rápido processo de modernização por que passou a sociedade brasileira durante o regime militar. Nesse processo verificase não apenas um crescimento quantitativo de novos atores, mas também que esses novos atores constituíram-se social, cultural e politicamente de maneira diferenciada, na medida em que a urbanização crescente provocou a introdução de novos hábitos. Ao lado da constituição de um associativismo civil urbano, outros dois movimentos exerceram um papel fundamental nesse processo, trata-se do novo sindicalismo e do associativismo profissional de classe média. 
Mas de que maneira esses movimentos sociais contribuem para o processo de políticas públicas? A capacidade de revitalização e ampliação da participação da sociedade civil nesse processo não se encerra com a constituição de movimentos sociais autônomos, carecendo ao mesmo tempo de canais institucionais para se expressarem. Concretamente, isso se daria com a possibilidade de apresentação de projetos de lei ou de políticas públicas por iniciativa das próprias instituições.

Portanto, diferentemente das abordagens correntes sobre as redes de políticas públicas, que focam a análise na capacidade ou mesmo na incapacidade do Estado em dar conta sozinho da formulação e da implementação das políticas, é preciso que ampliemos a configuração da análise a fim de incluir também a capacidade dos atores não-estatais em contribuir nesse processo. Não se trata de estabelecer condições normativas para a cooperação de atores diversos na execução de atividades públicas, mas tão somente alargar o escopo analítico para dar conta de uma realidade que, em alguns contextos, vai se tornando mais complexa. A maior complexidade aqui se refere ao fato de responsabilidades no ciclo de políticas públicas estarem sendo, em muitos casos, compartilhada entre atores públicos, privados e da sociedade civil. Nesse caso, se por um lado a execução das políticas tem a capacidade de, potencialmente, ganhar em eficiência, por outro lado, tem o efeito de introduzir novos elementos a desafiar a legitimação democrática da autoridade pública.

\section{III}

Nesta seção menciono dois exemplos de contextos de formulação e implementação de políticas públicas que serão avaliadas a partir da análise teórica da seção anterior. Em primeiro lugar, gostaria de mencionar um exemplo recente de implementação de política setorial sem a constituição de uma rede. Em segundo lugar, menciono um programa que se coloca a perspectiva de constituição de uma rede para sua implementação.

Tanto na Alemanha, quanto no Reino Unido, a implementação de políticas industriais tem se verificado como bastante propícia à constituição de redes de políticas públicas. Não é o caso do que encontramos pelo menos até recentemente, por exemplo, em Nova Serrana, Minas Gerais. A cidade de Nova Serrana, com 30.000 habitantes, está localizada a $133 \mathrm{~km}$ de Belo Horizonte. Até o início da década de 1950 o desenvolvimento se deu de maneira 
lenta, até que se iniciou a atividade de fabricação de calçados. A partir da década de 1980 este setor experimentou um rápido crescimento, baseado, sobretudo na falsificação de marcas conhecidas. Esse crescimento acelerado provocou ao mesmo tempo um aumento populacional desordenado, provocando problemas para o meio ambiente, para a oferta de moradia, oferta de vagas em escolas, lazer, serviços de saúde e saneamento.

Ao final da década de 1980, havia na cidade cerca de 350 empresas fabricantes de calçados, com a grande maioria delas apresentando baixa produtividade e sistema de gestão, comercialização e tecnologias rudimentares. Os calçados produzidos eram de baixa qualidade, a força de trabalho era mal remunerada e com alto nível de trabalho infantil. Desde que o mercado brasileiro de calçados foi aberto à competição internacional, o setor passou a se esforçar para melhorar os índices de qualidade e produtividade. No final da década de 1990, Nova Serrana era o terceiro pólo produtor de calçados do Brasil.

O maior problema identificado para o desenvolvimento futuro do setor foi justamente a baixa capacidade técnica da força de trabalho, tanto no chão de fábrica quanto do setor administrativo e comercial. Tanto a Prefeitura quanto o Sindicato dos Fabricantes de Calçados possuíam diagnóstico semelhante sobre a situação. Contudo, as iniciativas do poder público local e da entidade representativa dos fabricantes foram pontuais e, ainda mais grave, completamente desarticuladas uma da outra. O êxito desse tipo de política depende em grande medida do envolvimento daqueles setores atingidos pelas políticas. Assim, no caso de Nova Serrana, para superar os principais gargalos do setor calçadista exigia-se algumas medidas que passavam necessariamente pela ação conjunta e sistemática dos atores relevantes, entre eles a Prefeitura, o Sindicato dos Fabricantes, o Sindicato dos Trabalhadores, assim como as instituições educacionais locais e federal (CEFET - Centro Federal de Educação Técnica). Somente em anos mais recentes passou a ser construída uma tal alternativa, após a desobstrução do cenário político.

Por outro lado, outras experiências demonstram que a possibilidade de constituição de redes de políticas públicas está sendo explorada de maneira satisfatória. Dentre os programas executados atualmente pela Secretaria Estadual da Saúde do Rio Grande do Sul, o mais importante deles tem como objeto a redução da mortalidade infantil. Denominado "Primeira Infância 
Melhor" (instituído pela Portaria 15/2003, da Secretaria de Estado da Saúde, de 7 de abril de 2003), o Programa coloca em prática medidas de atenção integral às crianças de 0 a 6 anos de idade residentes nas zonas rurais e urbanas em situação de risco social. É nessa fase da vida, segundo o Programa, que vão se formar as bases essenciais do desenvolvimento físico, psicológico e da personalidade da criança. O programa "Primeira Infância Melhor" inspira-se em experiência semelhante existente em Cuba, onde o foco da atenção é promover o papel da família como protagonista na atenção a suas crianças. A execução do programa conta com o envolvimento de outras secretarias de Estado, porém não está à cargo exclusivamente dos órgãos governamentais, uma vez que desde o início já previa a participação permanente de associações comunitárias. Na primeira fase do programa, os responsáveis pelo programa buscaram parcerias com entidades da sociedade civil, além da constituição do Comitê Estadual para o Desenvolvimento Integral da Primeira Infância (instituído pelo Decreto N. 42.199 de 07 de abril de 2003). Fazem parte desse comitê, além de representantes de secretarias de Estado, entidades representativas do setor produtivo, dos municípios, de moradores de bairro, ONGs, a CNBB, dentre outras entidades. Na segunda fase constituíram-se Equipes Técnicas Municipais com caráter interinstitucional e intersetorial, além da constituição do Comitê Municipal da Primeira Infância dentre outras iniciativas.

Esta breve referência ao Programa Primeira Infância Melhor é relevante aqui para tornar explícito que os novos papéis tanto do Estado quanto da sociedade têm sido assimilados pelos gestores públicos no Brasil. Isso permite afirmar que o contexto político e social atual no Brasil, e especialmente no Rio Grande do Sul, tem apresentado as condições propícias para a constituição de redes de políticas públicas, não apenas pela incapacidade do governo de assumir sozinho as responsabilidades nesse empreendimento, como também pela maturidade institucional das organizações da sociedade civil gaúcha, além da capacidade - seja técnica, seja em capilaridade social - dessas instituições em contribuir satisfatoriamente para se alcançar metas não estatais, mas compartilhadas pelos mais diversos setores da sociedade. 


\section{Referências}

ABRANCHES, Sérgio. Política social, pobreza e desigualdade: a prática da teoria. In: ABRANCHES, Sérgio Henrique; SANTOS, Wanderley Guilherme dos; COIMBRA, Marcos Antônio. Política social e combate à pobreza. Rio de Janeiro: Jorge Zahar, 1987.

AVRITZER, Leonardo. Modelos de sociedade civil: uma análise da especificidade do caso brasileiro. In: MITRE, Antonio (org.). Ensaios de teoria e filosofia política. Belo Horizonte: DCP/UFMG, 1994.

CHAZEL, François. Movimentos sociais. In: BOUDON, Raymond (org.). Tratado de sociologia. Rio de Janeiro: Zahar, 1992.

COHEN, Jean; ARATO, Andrew. Civil society and political theory. Cambridge: The MIT Press, 1992.

COSTA, Sérgio. As cores de Ercília: esfera pública, democracia, configurações pósnacionais. Belo Horizonte: UFMG, 2002.

DINIZ, Eli. Uma perspectiva analítica para a reforma do Estado. Lua Nova, n. 45, p. 29-48, 1998.

HUNTINGTON, Samuel P. A ordem política nas sociedades em mudança. Rio de Janeiro: Forense, 1975.

LINDBLOM, Charles. Politics and markets. New York: Basic Books, 1977.

MARIN, Bernd; MAYNTZ, Renate (orgs.). Policy networks - empirical evidence and theoretical considerations. Frankfurt: Campus, 1991.

MARSHALL, T. H. Cidadania, classe social e status. Rio de Janeiro: Zahar, 1967.

OFFE Claus; RONGE, Volker. Teses sobre a fundamentação do conceito de 'Estado capitalista' e sobre a pesquisa política de orientação materialista. In: OFFE, Claus (org.). Problemas estruturais do Estado capitalista. Rio de Janeiro: Tempo Brasileiro, 1984.

PARSONS, Talcott. The social system. Glencoe: The Free Press, 1959.

PRZEWORSKY, Adam. Estado e economia no capitalismo. Rio de Janeiro: RelumeDumará, 1995.

SANTOS, Hermílio. Grupos de interesse e redes de políticas públicas. Civitas, Porto Alegre, EDIPUCRS, v. 1, 2002.

WEBER, Max. Politik als Beruf. Stuttgart: Reclam, 1993.

WILKS, Stephen; WRIGHT, Maurice (eds.). Comparative government-industry relations. Oxford: Claredon Press, 1987. 